\title{
O PROCESSO DE REESTRUTURAÇÃO DA AVICULTURA NO MATO GROSSO DO SUL: A RELAÇÃO ENTRE AS EMPRESAS JBS E BRF E OS PRODUTORES INTEGRADOS
}

Fábio de Lima ${ }^{1}$

Resumo: $O$ objetivo desse artigo é caracterizar o processo de reestruturação agroindustrial da avicultura no centro-sul de Mato Grosso do Sul, a partir das relações entre as empresas JBS e BRF e os produtores integrados. Com uma metodologia baseada em análise de dados e uma revisão bibliográfica, compreendemos que a presença destes grupos internacionalizados, tem provocado um processo de reestruturação da avicultura sul-mato-grossense. Para os avicultores, tem sido discutido uma nova etapa de produção, conhecida como sistema "Dark House", que exige um alto grau de investimento. Assim, a atuação dessas empresas internacionalizadas com investimentos do BNDES, pode gerar a concentração e centralização da produção de frangos, fazendo que alguns produtores se automatizem e aumentem suas escalas de produção, tornando-os mais capitalizados e, podendo acarretar na diminuição dos avicultores integrados insatisfeitos com a nova lógica de atuação dessas empresas.

Palavras-chave: Cerrado. Mato Grosso do Sul. Reestruturação agroindustrial. Agroindústria Avícola. JBS. BRF.

\section{THE PROCESS OF RESTRUCTURING AVICULTURE MATO GROSSO DO SUL: A RELATIONSHIP BETWEEN THE COMPANIES JBS AND BRF INTEGRATED PRODUCER}

Abstract: The objective of this article is characterize of process the agro-industrial restructuring of the poultry industry in south-central Mato Grosso do Sul, from the relations between JBS and BRF companies and integrated producers. The presence of these groups internationalized, has provoked a process of restructuring of the local poultry industry. For poultry farmers, it has been discussed a new production scale, known as "Dark House" system, requiring a high degree of investment. Thus, the actuation of these internationalized companies with BNDES investments can generate the concentration and centralization of chicken production, causing some producers automate and increase their production scales, making the best capitalized and may result in decrease in integrated poultry farmers dissatisfied with the new logic of actuation of these companies.

Keywords: Brazil. Mato Grosso do Sul. Agro-industrial restructuring. Poultry Agroindustry. JBS. BRF.

\footnotetext{
${ }_{1}^{1}$ Universidade Federal da Grande Dourados, Faculdade de Ciências Humanas, Dourados, Brasil, fabio_lima42@hotmail.com, https://orcid.org/0000-0002-0265-3924

2 Universidade Federal da Grande Dourados, Faculdade de Ciências Humanas, Dourados, Brasil, caroltorelli.faccin@gmail.com, https://orcid.org/0000-0001-8740-4689
} 


\section{EI PROCESO DE REESTRUCTURACIÓN DE LA AVICULTURA EN EI MATO GROSSO DO SUL: LA RELACIÓN ENTRE LAS EMPRESAS JBS Y BRF Y LOS PRODUCTORES INTEGRADOS}

Resumen: El objetivo de este artículo es caracterizar el proceso de reestructuración agroindustrial de la avicultura en el centro-sur de Mato Grosso do Sul, a partir de las relaciones entre las empresas JBS y BRF y los productores integrados. La presencia de estos grupos internacionalizados ha provocado un proceso de reestructuración de la avicultura local. Para los avicultores, se ha discutido una nueva etapa de producción, conocida como sistema "Dark House", que exige un alto grado de inversión. Así, la actuación de esas empresas internacionalizadas con inversiones del BNDES, puede generar la concentración y centralización de la producción de pollos, haciendo que algunos productores se automatizen y aumenten sus escalas de producción, haciéndolos más capitalizados $y$, pudiendo acarrear en la disminución de los avicultores integrados insatisfechos con la nueva lógica de actuación de esas empresas.

Palabras clave: Brasil. Mato Grosso do Sul. Reestructuración agroindustrial. Agroindustria Aviar. JBS. BRF.

\section{Introdução}

De acordo com o relatório da Associação Brasileira dos Produtores e Exportadores de Frangos (UBABEF), o Brasil foi o terceiro maior produtor de carne de frango no ano de 2013, perdendo apenas para a China e os Estados Unidos e China, primeiro e segundos colocados no mesmo ranking. Porém, o Brasil segue sendo o maior exportador de frangos no mundo, seguido pelos Estados Unidos e pela União Europeia (27 países). Cabe ressaltar que, nesse mesmo ano, 68,4\% da produção foi destinada ao mercado interno e 31,6\% teve como destino a exportação (UBABEF, 2014).

Maia (2008) aponta que essa posição de prestígio do Brasil no cenário internacional como se deve à grande disponibilidade de insumos como o milho e a soja no território nacional, pois os subprodutos derivados desses cultivos são indispensáveis na ração de frangos, o que favorece grandemente o desempenho do setor avícola no País.

Os principais estados abatedores de carne de frango no ano de 2013 foram o Paraná (31,12\%), Santa Catarina (16,66\%), Rio Grande do Sul (14,56\%), São Paulo $(10,99)$, Minas Gerais (7,66\%), Goiás (6,77\%), Mato Grosso (4,87\%) e Mato Grosso do Sul (3,04\%) (UBABEF, 2014). Já o ranking das cinco maiores empresas brasileiras exportadores de frangos em 2013, ficou assim estabelecido: 1ㅇ BRF

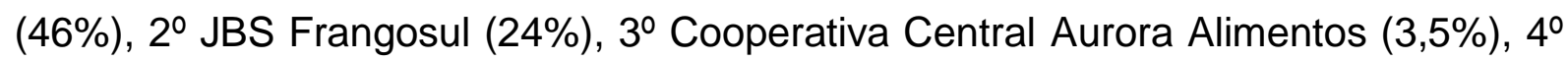
Tyson Foods (2,3\%) e 5으. Cale Cooperativa Agroindustrial (2,1\%) (UBABEF, 
2014). Por esses dados podemos concluir que apenas duas empresas, JBS e BRF, são responsáveis por $70 \%$ da exportação de carne de frangos no Brasil.

Nesse contexto, o estado de Mato Grosso do Sul, vem desenvolvendo a avicultura industrial desde o final dos anos 1980, com a chegada de frigoríficos de frango vindos da região Sul do País. Atualmente esse setor está entre as principais atividades agroindustriais do estado, sendo a carne de frango o sexto produto mais exportado (correspondendo a US\$ 314.543.262), representando 6\% do total exportado por Mato Grosso do Sul no ano de 2014.

Com a introdução de novas técnicas agrícolas no uso do território, principalmente nas áreas de domínio de Cerrado, a região Centro-Oeste passou a ser uma das maiores produtoras de grãos do país. Em relação ao estado de Mato Grosso do Sul, temos que a expansão da agroindústria para o sua região centro-sul foi motivada principalmente pela produção de grãos, pela minifundiarização antifuncional ao capital agroindustrial nos estados meridionais, pela disponibilidade de mão-de-obra e incentivada pelos programas de governo voltados ao desenvolvimento regional nos anos setenta.

Assim, o estado de Mato Grosso do Sul, inserido na região Centro-Oeste juntamente com mais outros dois estados (Goiás e Mato Grosso) e o Distrito Federal, configura-se entre os cinco principais produtores de grãos (soja e milho) do Brasil (CONAB, 2012), justificando sua inserção no "circuito espacial da produção" (SANTOS, 1986; MORAES, 1991; SANTOS \& SILVEIRA, 2001; CASTILLO \& FREDERICO, 2010; ARROYO, 2012) no contexto das agroindústrias. Segundo Rizzi (1999), através dos grãos - soja e milho - se obtém uma série de produtos destinados à alimentação humana e animal. O farelo é o principal subproduto em termos de extração de proteínas, que são transformadas em proteína animal (ração para aves e suínos).

Para compreendermos o circuito espacial da produção avícola, onde estão envolvidos uma série de fatores: A) a produção e disponibilidade dos grãos (soja e milho) essenciais na elaboração da ração; B) a transformação industrial aplicada aos grãos (ou seja, o momento da integração entre os setores agrícolas e industriais); C) a origem do material genético do frango (onde é obtido o fornecimento do frango matriz); D) o fornecimento dos pintos de-um-dia aos avicultores; E) a relação entre a empresa integradora e os produtores integrados; F) a chegada dos frangos em idade de abate nos frigoríficos e a manipulação destes por parte das empresas e, por último G) a distribuição no mercado consumidor (exportação ou mercado interno). 
O início da instalação dos abatedouros de frangos no estado (mapa 1) ocorreu com impulso do capital regional, com incentivo à integração dos produtores e linhas de financiamento subsidiadas para a implantação de barracões de alojamento de pintos. Com o passar dos anos, o aumento da capacidade das plantas industriais requereu outra organização produtiva, que tem primado pelo achatamento dos preços ao produtor, favorecido pela modernização dos aviários devido a sua total automatização no processo de criação (sistema Dark House).

Mapa 1 - Unidades abatedoras de carne de frango no Mato Grosso do Sul, 2015

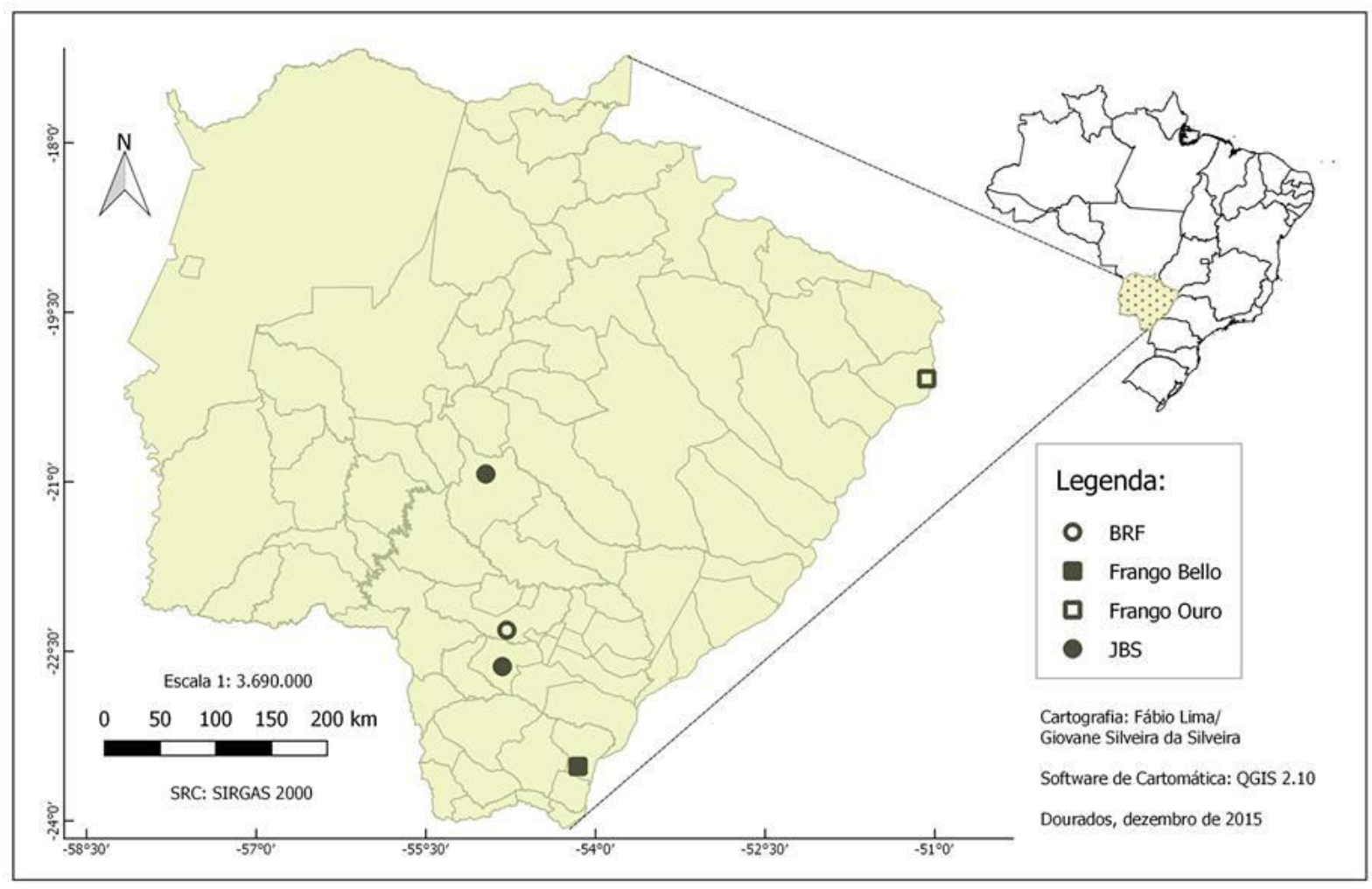

Recentemente, a comercialização da produção de carne de frangos está sendo imposta por grupos internacionalizados que atuam no centro-sul do estado de Mato Grosso do Sul, como é o caso das empresas BRF e JBS. Estas receberam financiamentos do Banco Nacional de Desenvolvimento Econômico e Social (BNDES) para se expandirem, o que as tornou mais competitivas no mercado internacional.

Com uma metodologia baseada em análise de dados das referidas empresas, entrevistas com produtores locais e revisão teórica pautada em farta bibliografia relacionada à temática de estudo, organizamos este artigo nos debruçando, 
inicialmente, em questões de ordem teórica, tendo como foco os circuitos espaciais de produção para discutirmos o atual setor avícola sul-mato-grossense. Após uma periodização do estabelecimento das primeiras empresas e situação da avicultura em Mato Grosso do Sul nas últimas décadas damos destaque à efetiva reestruturação produtiva ocorrida em certas porções do estado, alertando sobre a delicada relação entre as empresas e os produtores integrados, que se encontram em uma posição de cada vez maior vulnerabilidade.

\section{Questões de ordem teórica e os circuitos espaciais da produção}

Sem dúvida o espaço do setor avícola sul-mato-grossense está sob domínio técnico-científico das empresas transnacionais BRF e JBS, que notadamente comandam a atividade no estado. Para Santos (1993) o meio técnico-científico pode ser caracterizado pela soma da tecnosfera e da psicosfera: a tecnosfera resultaria da artificialização do meio ambiente, ou seja, significaria que a sua instalação representa a substituição do meio natural que a precedeu; a psicosfera, por sua vez, resultaria das crenças, desejos, vontades e hábitos, isto é, da adequação dos comportamentos sociais às tecnologias modernas. Assim, o "meio geográfico, que já foi 'meio natural' e 'meio técnico', é, hoje, tendencialmente, um meio 'técnicocientífico" (SANTOS, 1993, p. 17).

Se faz necessário refletir sobre a constituição de um meio geográfico a partir do estabelecimento das agroindústrias de aves, desenvolvido através de um modelo científico globalizado que não modifica apenas a produção avícola em si, mas também altera as relações sociais, visto que este modelo exige ciência, técnica e informação interligados a uma escala global de produção e distribuição dos produtos.

Nesse caso, o espaço geográfico constituiria a base da difusão de inovações tecnológicas e tal reflexão é importante para os estudos em Geografia por permitir esclarecer sobre como determinadas formas de modernização se instalam onde estão hoje presentes (SANTOS, 2003), a exemplo das frações do território onde o meio técnico-científico-informacional tem projetado sua força/potência (SANTOS, 1998).

É importante ressaltar que o processo de modernização da agricultura, consolidado por uma estratégia de Estado que visava o desenvolvimento do complexo agrícola em território sul-mato-grossense a partir da década de 1970, 
resultou, no final dos anos 1980, na diversificação e/ou agregação de valor na produção de grãos (soja e milho), promovendo sua associação com a cadeia de carnes de frango e suínos.

Para Bernardes (2010, p.15)

Se a expansão da produção de grãos nas últimas décadas havia instituído uma significativa fronteira do capital, recentemente novas especializações produtivas se impõem, constituindo a cadeia de carnes um novo front, envolvendo a revolução genética na produção de frangos, suínos e bovinos, traduzida em tecnologias de ponta, que produzem impactos no campo e na cidade, estabelecendo novas relações (BERNARDES, 2010, p.15).

A autora prossegue discorrendo sobre os impulsos de modernização, ressaltando que "as forças produtivas agroindustriais vêm se reorganizando, apresentando maior complexidade, o que pode ser detectado através dos novos circuitos espaciais de produção e dos círculos de cooperação" (BERNARDES, 2010, p.15). O circuito espacial de produção envolveria a dimensão geográfica dos processos de acumulação distribuídas nas etapas de produção, distribuição, comércio e consumo, ou seja, desde o início do processo de produção até o seu consumo final (CASTILLO \& FREDERICO, 2010; SANTOS, 1986; SANTOS \& SILVEIRA, 2001).

Em consonância com Santos \& Silveira (2001, p.144), temos que

circuitos espaciais da produção e círculos de cooperação mostram o uso diferente de cada território por parte das empresas, das instituições, dos indivíduos e permitem compreender a hierarquia dos lugares desde a escala regional até a mundial (SANTOS \& SILVEIRA, 2001, p. 144).

Em muitos dos casos, esses circuitos espaciais de produção, são formados por centros de poder ou comando que não necessariamente ocorrem no próprio local, e sim, por agentes de lugares distantes, ou até fora do país de origem.

\section{Estabelecimento e situação atual da agroindústria do setor avícola em Mato Grosso do Sul}

Segundo Mizusaki (2009), o desenvolvimento da avicultura em Mato Grosso do Sul pode ser dividido em três fases. A primeira, até 1988, foi quando a atividade se encontrava sob domínio do capital comercial e era desenvolvida para autoconsumo e gerava um pequeno excedente. A presença de matadouros nessa fase era quase inexistente, bem como a comercialização de frangos, que se dava nas cidades próximas e era feita diretamente com os comerciantes. Na segunda 
fase, entre 1989 e 1995, também analisada por Mizusaki (2009), houve o início da produção avícola em moldes industriais no próprio estado, o que evidenciava o processo de monopolização do território pelo capital, através de empresas de capital regional, sujeitando a renda da terra ao domínio do capital industrial. Na terceira e atual fase, inaugurada a partir de 1995, iniciou-se a atuação do capital monopolista, que, em um primeiro momento, era de origem nacional e, posteriormente, veio da participação de empresas transnacionais, provocando novas transformações na avicultura do estado (MIZUSAKI, 2009).

É relevante considerarmos alguns fatores presentes para a instalação da avicultura em escala industrial no estado. Como ressalta Mizusaki (2009), a abundância da mão-de-obra familiar, principalmente na região centro-sul do estado, acabou facilitando a implantação do sistema de integração empresa-produtor. A disponibilidade de matéria-prima, no caso a soja e o milho, como aponta Rizzi (1999), também foi fator chave, pois são componentes básicos da ração, correspondendo a $80 \%$ dos insumos utilizados na avicultura de corte. Em suma, são facilitadores para existência de indústrias no complexo de frangos e seus derivados. E, por fim, há uma posição geográfica favorável em relação aos grandes centros consumidores, principalmente aos estados da Região Sudeste e aos países do Mercosul. Em resumo, são fatores de destaque para a implantação da atividade avícola no estado de Mato Grosso do Sul.

Segundo Favaret Filho e Paula (1998), ao produzir grãos mais baratos que os estados da Região Sul, a Região Centro-Oeste promoveu a redução dos custos produtivos e incentivou a produção de suínos e aves. Esse processo acabou por gerar uma sucessão de aquisições de empresas regionais por grupos de fora do estado e também a instalação de agroindústrias em Mato Grosso do Sul.

Savoia (2009) registra alguns fatores para explicar o incremento da produção agrícola nos últimos anos. Pode-se considerá-los para compreendermos a expansão das corporações no Mato Grosso do Sul: disponibilidade de máquinas devido ao apoio do Banco Nacional de Desenvolvimento Econômico e Social (BNDES), condições favoráveis para maior rentabilidade da produção de soja, condições climáticas, investimentos públicos e privados em pesquisas, baixo custo da mão-deobra, profissionalização do setor, investimentos em infraestrutura e política agrária.

Lamoso (2010), em pesquisas sobre o comércio exterior de Mato Grosso do Sul, elencou a possibilidade de um fortalecimento das exportações, já que se trata de uma expansão da exportação de semimanufaturados pela BRF; haveria assim 
fatores que justificam a investigação a respeito do fortalecimento da agroindústria, em particular, no município de Dourados.

O Mato Grosso do Sul acentuou sua inserção internacional exercendo o papel de fornecedor de mercadorias consideradas como bens primários, parte delas como commodities. Predominam na pauta exportadora as mercadorias do complexo soja (grãos, bagaço e resíduo, subproduto da extração do óleo), pedaços e miudezas de galinha, minério de ferro, carne bovina desossada entre outros. (LAMOSO, 2010, p.3).

A primeira empresa abatedora de aves a entrar em funcionamento no estado estava localizada na região de Dourados e se formou a partir da rede de cooperados agrícolas, com o nome de COOAGRI (Cooperativa Agropecuária e Industrial Ltda). Criada no início dos anos 90, a COOAGRI se formou após o desmembramento de outra cooperativa, a COTRIJUÍ, originária da cidade gaúcha de ljuí, fundada em 20 de julho de 1957.

Em 1995, a AVIPAL S/A adquiriu a COOAGRI, que detinha um abatedouro de aves, fábrica de rações e uma estrutura de armazenagem de grãos e interação avícola no município de Dourados.

No ano de 2006, as marcas Avipal e Elegê se uniram para formar a Eleva Alimentos, com a intenção de diversificar seus produtos e dominar o mercado para o qual comercializavam. No ano de 2007 a Perdigão incorporou o Grupo Eleva ao seu domínio, com o objetivo de abrir vantagem em relação à empresa Sadia, que era sua maior concorrente de mercado. Com os problemas financeiros enfrentados pela empresa Sadia, decorrentes da crise norte-americana que afetou grande parte do mundo em 2008, a Perdigão decidiu comprar $51 \%$ de suas ações e criando o Grupo Brasil Foods (BRF).

Como aponta Almeida (2009, p. 30), o BNDES foi o principal financiador desta importante operação. Cita o autor que "em 2008, o BNDES emprestou por meio de operações diretas $R \$ 342,7$ milhões para a Perdigão e $R \$ 329,8$ milhões para a Sadia". Somando o montante das duas empresas obtemos o total de $\mathrm{R} \$ 672,5$ milhões emprestados pelo BNDES apenas no ano de 2008, sendo a quarta posição entre as maiores operações diretas do BNDES naquele ano. Segundo o autor, "o BNDES possui $3 \%$ do capital da nova Brasil Foods, uma empresa que nasceu com 116 mil funcionários, 42 fabricas, 10 bilhões de exportações anuais e um faturamento anual líquido de R\$ 22 bilhões" (ALMEIDA, 2009, p. 31). Esta empresa configura-se entre as dez maiores empresas alimentícias das Américas em valor de mercado. 
Em um contexto mais regional, há o caso da empresa Piratini, que entrou em funcionamento no ramo da avicultura em 1991, no munícipio de Caarapó-MS e que possuía uma capacidade de abate diário de 35 mil aves e era administrada por empresários locais até 1996, ano de sua venda para a empresa Frangosul (de capital nacional com sede em Montenegro-RS). No ano de 1998, a Frangosul foi adquirida pelo grupo de capital francês Doux, passando a denominar-se DouxFrangosul (LOMBA, 2011). Uma das lógicas capitalistas do grupo ao territorializar-se no estado foi sua inserção no mercado internacional de aves, destinando $50 \%$ da produção ao mercado externo, principalmente ao Oriente Médio, e o restante para mercados internos, com destaque para São Paulo e Manaus.

A JBS iniciou sua operação no segmento de aves no Brasil por meio do arrendamento dos ativos da Doux-Frangosul em 2012, o que elevou em 15\% sua capacidade global de abate. Uma das unidades arrendadas pelo grupo JBS está localizada no município de Caarapó-MS, com capacidade de abater 160 mil frangos por dia.

A empresa Agroeliane, inaugurada em 1993 no município de Sidrolândia-MS, possuía uma estrutura industrial com capacidade de abate de 60 mil aves por dia, além de compreender alojamento para matrizeiros, incubatório e uma fábrica de ração (MIZUSAKI, 2009). Em 1995 foi incorporada pelo grupo Ceval e, três anos depois, a unidade passou a pertencer a Seara Alimentos. No ano de 2005 o grupo Cargill assumiu o controle acionário da Seara (PIVA et al, 2007) e, em 2009, o controle da Seara passou a ser realizado pela Marfrig. Recentemente, em 2013, a JBS adquiriu a marca Seara (anteriormente domínio do grupo Marfrig), expandindo suas operações de frangos e suínos no país e acirrando a competição no mercado doméstico. A compra da marca Seara somou-se a uma importante estratégia expansionista do grupo JBS, pois garantiu uma participação relevante no mercado internacional de aves. No exterior a JBS lidera a produção de carne de frangos, com 8,5 milhões de aves abatidas por dia.

É importante ressaltarmos nesse contexto de fusões/aquisições do grupo JBS o aporte fundamental de recursos financeiros oriundos do BNDES, o que possibilitou o fortalecimento desse grupo via compra de outros frigoríficos com dificuldades financeiras para sobreviver no mercado nacional e internacional.

De acordo com Rocha (2014, p.91), 
do BNDES, cuja participação direta na empresa atualmente é de $17,02 \%$ (ROCHA, 2014, p.91).

O grupo JBS, que até 2005 não contava com nenhuma operação no exterior, atualmente é a maior empresa no setor de frigoríficos do mundo (ROCHA, 2014). Iniciou seu processo de expansão internacional justamente em 2005 com a compra da unidade da Swift na Argentina (com financiamento do BNDES) e, posteriormente, a incorporação da matriz americana Swift Foods and Company por US $\$ 1,4$ bilhões em 2007, também com financiamento estatal (ALMEIDA, 2009).

\section{Reestruturação produtiva e a relação entre as empresas e os produtores integrados}

Dentre os setores envolvidos na produção do agronegócio brasileiro podemos considerar a avicultura industrial umas das atividades mais desenvolvidas tecnologicamente, sobretudo pelo progresso técnico empregado em genética, nutrição, manejo e sanidade avícola (TINOCO, 2001). É razoável salientar que, em virtude desse nível de avanço tecnológico, este setor é marcado por constantes evoluções técnicas, constituindo assim uma importante conquista de ampliação de seu mercado consumidor e expansão geográfica de sua produção.

Por sua vez, essa difusão de inovações alteraram a organização espacial de maneira profunda, pois novas áreas podem ser incorporadas ao circuito produtivo (ESPINDOLA, 2012). Atrelado a esse movimento de difusão de inovações a reestruturação produtiva pode ser vista como uma transformação espacial de ordem técnica ou das relações de trabalho na cidade (indústrias) ou no campo (agroindústrias).

No Brasil teve seu início principalmente a partir dos 1990, se aperfeiçoando no decorrer dos anos 2000. Destaca-se por seu potencial em gerar inovações tecnológicas, onde as médias e grandes empresas possuem papel de destaque se enquadrando no modelo de produção flexível. Gomes (2011) caracterizou esse processo por dois fatores: 1) crise econômica no mercado interno e, 2) abertura econômica no governo Fernando Collor de Mello.

Podemos considerar a reestruturação produtiva da avicultura em Mato Grosso do Sul correspondente a um processo mais amplo de mudanças no âmbito nacional e mundial. Como assinalado por Mizusaki (2007, p.138), 
após a entrada das empresas de maior porte no Estado a partir de meados dos anos de 1990, verificamos que houve um processo de reestruturação produtiva na avicultura em Mato Grosso do Sul, acentuando a entrada de novas categorias de produtores na avicultura, introduzindo assim, novas relações de trabalho e produção na atividade avícola (MIZUSAKI, 2007, p.138).

Nos aviários, de acordo com Mizusaki (2007), as transformações se deram no interior dos barracões, com a introdução de novas técnicas no cuidado com os pintinhos aliados a uma maior quantidade de equipamentos como comedouros, bebedouros e ventiladores, auxiliando um melhor controle da temperatura e possibilitando um maior alojamento de frangos, aumentando de maneira direta a produtividade. Nesse sentido, para "a adequação da nova estrutura, uma vez que não possuíam recursos para tal, os avicultores normalmente tinham que realizar outro financiamento no banco" (MIZUSAKI, 2007, p.139), sendo esta uma imposição por parte da empresa que exercia seu "poder de mando" no território", expressão de Santos (1998).

No ano de 2013, Mato Grosso do Sul contava com um total de 496 produtores integrados as empresas abatedoras de frangos. O maior número de produtores integrados encontrava-se na JBS, que possui duas unidades de abatedouro no estado: um em Sidrolândia (anteriormente em poder do grupo Marfrig) e outro em Caarapó (resultado do arrendamento da Doux-Frangosul pelo JBS). Somando, as duas unidades possuem 261 produtores integrados, seguida pela BRF instalada em Dourados (197 integrados), Frango Bello no município de Itaquiraí (23 integrados) e Frango Ouro na cidade de Aparecida do Taboado (15 integrados). A evolução desses números pode ser conferida na tabela 1 , que mostra 0 total de produtores integrados de 1998 a 2013.

Tabela 1- Total de avicultores integrados as agroindústrias no Mato Grosso do Sul 1998-2013

\begin{tabular}{|c|c|c|c|c|}
\hline \multirow{2}{*}{ EMPRESA } & \multicolumn{4}{|c|}{ № de integrados } \\
\cline { 2 - 5 } & $\mathbf{1 9 9 8}$ & $\mathbf{2 0 0 2}$ & $\mathbf{2 0 0 7}$ & $\mathbf{2 0 1 3}$ \\
\hline $\begin{array}{c}\text { Avipal/Perdigão/BRF } \\
\text { (Dourados) }\end{array}$ & 316 & 322 & 170 & 197 \\
\hline $\begin{array}{c}\text { Doux Frangosul/JBS } \\
\text { (Caarapó) }\end{array}$ & 139 & 145 & 149 & 113 \\
\hline $\begin{array}{c}\text { Seara/JBS } \\
\text { (Sidrolândia) }\end{array}$ & 133 & 149 & 196 & 148 \\
\hline $\begin{array}{c}\text { Frango VIT/Comaves } \\
\text { (Campo Grande) }\end{array}$ & 84 & 112 & 55 & - \\
\hline $\begin{array}{c}\text { Frandelle/Frango Bello } \\
\text { (Itaquiraí) }\end{array}$ & 20 & 18 & 14 & 23 \\
\hline
\end{tabular}




\begin{tabular}{|c|c|c|c|c|}
\hline $\begin{array}{c}\text { Frango Ouro } \\
\text { (Aparecida do Taboado) }\end{array}$ & 18 & 18 & 20 & 15 \\
\hline TOTAL & $\mathbf{7 1 0}$ & $\mathbf{7 6 4}$ & $\mathbf{6 0 4}$ & $\mathbf{4 9 6}$ \\
\hline
\end{tabular}

Fonte: MIZUSAKI (2009); FAMASUL (2014). Elaboração própria dos autores.

Percebe-se, a partir do início da década de 2000, um decréscimo considerável no número de avicultores no Mato Grosso do Sul. Passando de 764 avicultores em 2002 para 496 em 2013, há uma diminuição de 36\% em apenas 11 anos, o que denota uma nova reorganização espacial da produção avícola no estado. Somando os produtores integrados as duas empresas JBS e BRF obtemos um total de 458 avicultores, o que representa $92 \%$ dos produtores integrados submetidos às normas dos grupos internacionalizados, o que indica grande vulnerabilidade territorial, entendida por Faccin \& Castillo (2017) como uma vulnerabilidade que atinge o aspecto econômico, social, político e ambiental.

Com o advento do capitalismo industrial na avicultura de corte sul-matogrossense, todo o processo produtivo da carne de frango passou a ser controlado pela indústria de corte. O capital industrial incorporou todas as fases do processo produtivo, desde o nascimento dos pintos de um dia - englobando as mutações genéticas para acelerar o seu crescimento natural - até o seu último dia de vida no processo de abate, realizado no frigorífico. Isso ocorre, principalmente, através da apropriação do trabalho, no sistema de supostas "parcerias", integrando o produtor com a empresa contratante e monopolizando a produção em escala industrial. Assim, a empresa não precisa necessariamente comprar terras para incorporar sua produção e passa a intermediar essa ação no campo, com participação de avicultores que concordam em serem parceiros da empresa.

Verificamos nessa postura da empresa contratante uma estratégia para escapar dos riscos na criação de frangos, transferindo-os diretamente para o produtor. Assim, as empresas não têm despesas com a mortalidade de frangos por exemplo, ou qualquer outro problema sanitário que a criação possa enfrentar, como eventuais doenças.

A partir de 2013 um momento de crise se instalou na avicultura regional. Entende-se que uma vez que empresa é internacionalizada ela tem a necessidade de aumentar a escala de produção e participar do comércio internacional com exportações para diversos países. Nesse contexto, tem sido discutido uma nova etapa de produção para os integrados, conhecida como sistema "Dark House", que difere do modelo anterior de produção por possibilitar um aumento da capacidade de 
alojamento, com controle preciso de temperatura e condições gerais de luz e ambientação da criação. Atualmente há projetos para implantação de aviários novos nesse sistema nas regiões dedicadas à avicultura no estado de Mato Grosso do Sul. Os custos são altos e, para se alcançar viabilidade produtiva em uma área, são considerados a construção de 4 módulos para alojamento de até 130 mil frangos no mínimo, a um custo estimado de $\mathrm{R} \$ 4.200 .000,00$.

A grande diferença entre o sistema de produção dito convencional ou semiautomatizado para o sistema "Dark House" é que no segundo os frangos são criados com luminosidade controlada, permitindo uma maior densidade de aves por metro quadrado de galpão, mantendo as aves mais calmas, evitando assim dermatoses e permitindo uma menor conversão alimentar e melhor ganho de peso diário, o que traz um melhor resultado zootécnico e maior retorno financeiro à empresa e produtores (GALLO, 2009). A tendência da produção tida como tradicional nesse setor, frente a essa moderna forma de produção, se mostra pessimista e com poucas chances de manutenção de custos de produção e comercialização, fazendo com que os pequenos se endividem ao tentar competir com os grandes e concentrando ainda mais a avicultura no domínio das grandes empresas internacionalizadas.

No que se refere aos avicultores há um alto risco e tendência ao endividamento dos produtores menos capitalizados, que teriam que recorrer à linhas de financiamento estatal. Um conjunto de produtores integrados estava com financiamento empenhado no Banco do Brasil nos últimos quinze anos, em função da construção de seus atuais barracões e muito recentemente, esses financiamentos foram quitados. O novo patamar de endividamento, que fará a drenagem da renda ao sistema financeiro, provoca um sentimento de insegurança, visto que não há compromisso da empresa em continuar com a aquisição dos frangos, pois isso dependerá das condições de mercado.

Assim, a atuação de destas empresas internacionalizadas que contam com investimentos do BNDES no setor avícola no centro-sul de Mato Grosso do Sul, pode gerar a futura concentração e centralização da produção de frangos, fazendo com que os produtores no início da cadeia se automatizem, aumentando suas escalas de produção, tornando-os mais capitalizados e podendo acarretar na diminuição dos avicultores integrados insatisfeitos com a nova lógica de atuação dessas empresas. 


\section{Considerações Finais}

Nas últimas décadas houve um contundente processo de restruturação da avicultura no estado de Mato Grosso do Sul. O ambiente agrícola favorável principalmente na região centro-sul do estado, que conta com alta produção especializada em grãos como a soja e o milho, aliado a políticas estatais focadas na consolidação de uma agroindústria, principalmente via financiamentos por meio do Banco Nacional de Desenvolvimento Econômico e Social (BNDES). Nesse contexto, a produção de carne de frangos passou pela produção regional e, atualmente, encontra-se sob domínio de grupos internacionalizados que atuam em Mato Grosso do Sul, como as empresas BRF e JBS. Estas receberam financiamentos para se expandirem, o que as tornou mais competitivas no mercado internacional, estabelecendo normas e diretrizes produtivas aos produtores locais. Assim, a presença dos grupos internacionalizados tem provocado um processo de reestruturação da avicultura no território de Mato Grosso do Sul e para os produtores integrados, ou seja, os responsáveis pela criação do frango, tem sido imposto um novo modelo de produção conhecido como sistema "Dark House", o que exige do produtor um alto grau de investimento, deixando os que não podem participar desse movimento moderno vulneráveis e com poucas chances de sobrevivência no atual cenário da avicultura sul-mato-grossense.

\section{REFERÊNCIAS}

ALMEIDA, Mansueto. Desafios da real política industrial brasileira do século XXI. Textos para Discussão IPEA - n,1452. Brasília, 2009. Disponível em <http:// www.ipea.gov.br/sites/000/2/publicacoes/tds/td_1452.pdf>. Acesso em 15 jan. 2010.

ARROYO, Mônica. Circuitos espaciais de produção industrial e fluxos internacionais de mercadorias na dinâmica territorial do estado de São Paulo. Boletim Campineiro de Geografia, Campinas, v. 2, n. 1, p. 07-26, fev, 2012.

BERNARDES, Júlia Adão O novo tempo do capital no cerrado: a criação de novos territórios produtivos. In: BERNARDES, J.A.; ARACRI, L.A. dos S. Espaços e circuitos produtivos. A cadeia carne/grãos no cerrado mato-grossense. Rio de Janeiro: Arquimedes Edições, 2010.

CASTILLO, Ricardo Abid; FREDERICO, Samuel. Espaço geográfico, produção e movimento: uma reflexão sobre o conceito de circuito espacial produtivo. Sociedade e Natureza. Uberlândia, v. 22, n. 3, p. 461-474, dez, 2010.

CONAB - ACOMPANHAMENTO DA SAFRA BRASILEIRA GRÃOS 2012/2013, CONAB 2012 disponível < www.conab.com.br > acesso em 09/05/2015.

ESPÍNDOLA, Carlos José. Trajetórias do progresso técnico na cadeia produtiva de carne de frango do Brasil. Revista Geosul, v. 27, n. 53, p. 89-113, jan./jul., 2012. 
FACCIN, Ana Carolina Torelli Marquezini; CASTILLO, Ricardo Abid, A. Vulnerabilidade territorial e implicações sócio-espaciais da expansão do complexo soja no Mato Grosso do Sul. Estudos Geográficos (UNESP), v.15, p.133 - 156, 2017.

FAVARET FILHO, Paulo; PAULA, Sergio Roberto Lima de. Um estudo da integração a partir do projeto Buriti, da Perdigão, BNDES Setorial. Rio de Janeiro, n.7, p.123-134. 2000.

GALLO, Bernardo Bocchese. Dark House: manejo $x$ desempenho frente ao sistema tradicional. In: SIMPÓSIO BRASIL SUL DE AVICULTURA, 10, 2009, Chapecó, SC. Anais do X Simpósio Brasil Sul de Avicultura e I Brasil Sul Poultry Fair. Concórdia: Embrapa Suínos e Aves, 2009, 140p.

GOMES, Maria Terezinha Serafim. Reestruturação produtiva e suas implicações na indústria do oeste paulista. In: VIDEIRA, Sandra Lúcia; COSTA, Pierre Alves; FAJARDO, Sérgio (org). Geografia Econômica: (re)leituras contemporâneas. Rio de Janeiro: Letra Capital, 2011. $193 \mathrm{p}$.

LAMOSO, Lisandra Pereira. Comércio exterior brasileiro: a tese da "reprimarização" da pauta exportadora e suas repercussões para mato grosso do sul. In: XVI ENCONTRO NACIONAL DE GEÓGRAFOS, 2010. Porto Alegre. Anais XVI Encontro Nacional de Geógrafos. Porto Alegre: UFRGS, 2010.

LOMBA, Roni Mayer. Relacão campo-cidade na pequena cidade de Caarapó-MS. Tese de doutorado em Geografia Humana - Faculdade de Filosofia Letras e Ciências Humanas, Universidade de São Paulo, 239 f. 2011.

MAIA, Paulo Roberto. Estratégias Corporativas da Indústria de frangos - Um estudo exploratório. 2008. 110 f. Dissertação (Mestrado em Ciências Contábeis) - Faculdade de Administração e Finanças, Universidade do Estado do Rio de Janeiro, Rio de Janeiro, 2008.

MIZUSAKI, Márcia Yukari. Território e reestruturação produtiva na avicultura. Dourados: Editora da UFGD, 2009.

MIZUSAKI, Márcia Yukari. Reestruturação produtiva na avicultura em Mato Grosso do Sul. Geosul. Florianópolis, v. 22, n. 44, p. 135-154, jan. 2007. Disponível em: <https://periodicos.ufsc.br/index.php/geosul/article/view/12613/11776>. Acesso em: 08 Jun. 2015. doi:http://dx.doi.org/10.5007/12613.

MORAES, Antônio Carlos Robert. Los circuitos espaciales de la producción y los círculos de cooperación en el espacio. In: Aportes para el estudio del espacio socio-economico III. Yanes, L. e Liberali, A. M. (orgs.). Buenos Aires, El Coloquio, 1991. p.153-77.

PIVA, Carla Dal. et al . Sistema de Gestão Ambiental implementado aos moldes da ISO 14001:2004 em um frigorífico de abate de aves, no município de Sidrolândia - Mato Grosso do Sul. Revista Brasileira de Gestão e Desenvolvimento Regional, v. 3, p. 20/3-53, 2007.

RIZZI, Adair Tarciso. A indústria de frangos no Brasil: constituição e transformações. In: III CONGRESSO BRASILEIRO DE HISTÓRIA ECONÔMICA, 1999, Curitiba. Economia Urbano Industrial. v. 1, p. 1-3, 1999.

ROCHA, Danilo. Estado, empresariado e variedades de capitalismo no Brasil: política de internacionalização de empresas privadas no governo Lula. Revista de Sociologia e Política (UFPR. Impresso), v. 22, p. 77-96, 2014. 
SANTOS, Milton. Circuitos espaciais da produção: um comentário. In: SOUZA, Maria Adélia Aparecida de; SANTOS, Milton. A construção do espaço. São Paulo: Nobel, 1986. p. 121134.

SANTOS, Milton. A aceleração contemporânea: tempo mundo e espaço mundo. In: Fim de século e globalização. HUCITC-ANPUR, São Paulo, SP. 1993.

SANTOS, Milton. Técnica, espaço, tempo: globalização e meio técnico-científicoinformacional. São Paulo: Hucitec, 1998.

SANTOS, Milton. Por uma outra globalização. Rio de Janeiro: Record, 2000, 174 p.

SANTOS, Milton; SILVEIRA, María Laura. O Brasil: território e sociedade no início do século XXI. Rio de Janeiro: Record, 2001. 473 p.

SANTOS, Milton. "Difusão de inovações ou estratégia de vendas?". In: Economia Espacial. São Paulo: Edusp, 2003, p.41-74.

SANTOS, Milton. Metamorfoses do espaço habitado: Fundamentos Teóricos e Metodológicos da Geografia, 6 ed. São Paulo: Edusp, 2008.

SAVOIA, José Roberto Ferreira. (org.) O agronegócio no Brasil: uma perspectiva financeira. São Paulo: Saint Paul, 2009. p-16.

TINOCO, Ilda de Fátima Ferreira. Avicultura industrial: novos conceitos de materiais, concepções e técnicas construtivas disponíveis para galpões avícolas brasileiros. Revista Brasileira de Ciência Avícola, Campinas, v. 3, n. 1, 2001.

UBABEF 2013. Relatório anual da união Brasileira de avicultura. Disponível em:<http://www.ubabef.com.br/files/publicacoes/732e67e684103de4a2117dda9ddd280a.pdf >. Acesso em: 29 out. 2014.

\section{NOTAS DE AUTOR}

\section{CONTRIBUIÇÃO DE AUTORIA}

Fábio de Lima - Concepção. Coleta de dados, Análise de dados, Elaboração do manuscrito, revisão e aprovação da versão final do trabalho

Ana Carolina Torelli Marquezini Faccin - Colaboração do manuscrito. Participação ativa da discussão dos resultados; Revisão e aprovação da versão final do trabalho.

\section{FINANCIAMENTO}

Bolsa de pesquisa CAPES-DS (cota do Programa de Pós-Graduação em Geografia/Faculdade de Ciências Humanas/Universidade Federal da Grande Dourados).

CONSENTIMENTO DE USO DE IMAGEM

Não se aplica.

\section{APROVAÇÃO DE COMITÊ DE ÉTICA EM PESQUISA}

Não se aplica.

CONFLITO DE INTERESSES

Não se aplica.

\section{LICENÇA DE USO}

Este artigo está licenciado sob a Licença Creative Commons CC-BY. Com essa licença você pode compartilhar, adaptar, criar para qualquer fim, desde que atribua a autoria da obra. 